\title{
Theatre Practice as a Model of Pedagogy in Nigerian Secondary Schools
}

\author{
Ilami Krama Clive, Phd \\ Media Sociology Lecturer Department Of Theatre And Film Studies University Of Port Harcourt Nigeria,
}

\begin{abstract}
Early child learning has improved the Child's learning abilities through animations and rhymes. This method improves the early child psychomotor and cognitive ability. However, the adult child in secondary school does not have such opportunities of further developing the cognative and psychomotor abilities. Therefore the aim of this paper is to examine how theatre practice can aid child learning in secondary schools. The use of theatre practice in science subjects is needful since these subjects have over the years been stumbling blocks to Nigeria's school children. Music, songs and drama have been used to teach the arts extensively. The methodology explored in this paper is exploratory, while the framework involves the subjecting of theatre practice as a theory and tool of pedagogy. The findings reveal that the early child earning improves with the extensive use of theatre practice. Thus there is need to employ theatre practice in the learning of science subjects that have been difficult for secondary schools.
\end{abstract}

Key words: Theatre, Practice, pedagogy, skills

\section{INTRODUCTION}

Most secondary school students in Nigeria loath the science subjects, while some see these subjects as difficult areas. Thus losing the opportunity to develop interest these areas. This has also led to the dearth of composite industries and skills in the development of learning resources. Subjects like mathematics, chemistry, physics and additional mathematics always become problematic for students. The use of the role play method in the early child learning processes enables the child to use dance, music and songs in learning science. Children hardly know that they are learning science when they sing or use rhymes in learning members, nature and even the environment. The play way method entails the use of imaginary situations and spontaneous interactions of the participants in acting out imaginary situations as school, family, market or medical doctors.

Drama, songs, music, mimes have been used extensively in school learning. The experiment promotes communication skills, problem solving skills and multisensory learning. Drama quickens the interest, imagination and creativity of students Chioma Chukueggu (2012:154) informs that:

The use of drama in language teaching has its theoretical basis on the socio-cultural theory proposed by a Russian Psychologist, Levygosky. Levygosky believes that children construct their own knowledge. One of his assumptions is that cognitive skills are mediated by words, language and forms of discourse which serves as tools for facilitating and transforming mental activities.

Sadly as this assumption may appear, the experiment has been limited to the study of language and communication skills. Therefore, the benefits of theatre practice as a tool of pedagogy will enhance the learning of the sciences and those core areas of learning that have proved difficult for the Nigerian secondary school student.

\section{Modes of Pedagogy}

The talk-chalk method has been the traditional means of imparting knowledge to school children in Nigeria. This practice has continued from the colonial to the Post colonial period. The colonial period introduced the talk-chalk method which was teacher centred. Igwe et-al (2014:15) affirms that In most of the technical institutions across the country, students are trained on obsolete technical equipment that simply cannot be matched with actual work situation.

The assumption above presents the gory tale of the models of pedagogy prevalent in Nigeria and which accounts for the massive failure of students. The outcry on the declaration of state of emergency on the education sector arises from the massive failure of students in the West African Examination and the Joint Matriculation Examination. On yearly basis the failure rate has been on the increase particularly in the science subjects. Most students see the sciences as no go area. When statistics on student performances are presented, the success rate in the humanities is always higher than the sciences. 
The model of pedagogy can really impede learning for several reasons. The method of teaching makes students generally unaware the knowledge they have is faulty. This so because a faulty process will of necessity produce a faulty product. The assumption here is that the massive failure is a product of the antiquated model of teaching of science subjects prevalent in Nigerian schools.

Nwanekezi et al (2014:23) also believe that:

Again teachers are faced with the challenge of identifying these misconceptions as well as bringing about significant conceptual change in students by use of instructional strategies.

The models of teaching do not only limit the students cognitive ability but also hamper the teachers effective delivery of the required capacity utilization. The talk-chalk model of teaching limits the teachers and produces trained incapacitation. When the students are made responsible for the acquisition of knowledge through proper methods of teaching, the students learns better.

Chioma Chukueggu (2012:151) asserts that:

The use of drama and dramatic activities in foreign and second language is not new. It has lasted for over a century but it came to the fore front in the last decade. However, this aspect of language teaching is neglected in Nigeria by language teachers, curriculum developers.

The point stressed here is that the teacher being the sage and stage model is underdeveloping the students and the teachers. The play way model which is neglected in Nigeria exposes students to a wide range of opportunities which sharpen skills, motivation and propensity for self discovery. The role play model stimulates the students intellect, imagination and creativity as well as enabling memory through direct experimentation. The little effort at imploring the role play model is limited to the arts, while the teaching of the sciences is still steep in premodial experimentation. It is a bit of luck and accident that most Nigerian students excel in the science subjects.

Chukwueggu and Umera-Okeke (2013:55) further explain that:

Students are constantly confronted with new information, particularly once they progress to upper elementary schools and secondary schools...students need to integrate new materials into their existing knowledge base, construct new understanding and adapt existing conceptions...

Actual experience is what accounts for the students development, motivation and interest in learning. To impact students memory, they must see, touch, use and experience real objects. The question begging for an answer is why has Nigerian education policy makers refused the incorporation of new models of pedagogy despite the numerous benefits. There is the need for policy and system overhaul to improve standards and pave the ground for proper learning of the student particularly the science subjects. Since the schema has succeeded in language and other arts subject, the same experience should be extended to the science students to graphic images as channels of learning. The Nigerian teacher in the sciences is always at a loss on how to impact knowledge to the few students offering science subjects and the way out is the use of theatre practice.

\section{Theatre Practice As A Model Of Pedagogy}

Ken-Aminikpo (2014:116) explains that:

These participatory theatre arts exercises may be infused into a wide variety of curricula, ranging in subject area from language learning to grades and cognitive levels are included in activities rich in content and in promoting self esteem.

The absence of theatre practice as a model of instruction is established in the position of Ken Aminikpo. The use of theatrical activities in teaching and learning provide motivation for the learner. It also encourages experimentation and development of cognitive skills. The use of the theatre as a model of learning provides the arousal of motivation, discipline, selection and achieve positive behavior. The lack of self esteem in science subjects by secondary school students can be improved upon when they internalize the knowledge. The knowledge of science can be appropriated when the students are motivated to experiment through play process. The schema has scored a huge success in language learning and therefore should be encouraged to be experimented in the science disciplines. As earlier noted that numbers are learnt through rhymes in the early primary stage of children.

The experimentation of theatricalities in the teaching of science subjects will enhance a collaboration between the students and the teacher and among the students. This also provides authentic environment that creates meaningful learning. Chioma and Umera-okeke (2013:46) affirm that:

A learner who indulges in organizing graphically is brainstorming. It has been discovered that one of the simplest methods for helping students activate background knowledge is to prompt them to bring to mind and state, write down or otherwise record what they know. 
Knowledge graphically presented creates metal pictures and aid the students memory. Methods in Algebra, Quadratic Equations, Organic Chemistry, Biology and Physics can be presented graphically or through rhymes, songs and even mimes to stimulate authentic learning in the students. The learning environment, the tools of learning and the manner of learning all combine to rob the Nigerian child. The same knowledge is presented to students abroad. However, Nigerian secondary school leavers record abysmal failure in the sciences and this has tremendous impact on the technological growth of the country. A lot of resources and man hours are spent by both parents as well as student in remedying failed examinations particularly in the science subjects. It is not as it were that the Nigerian secondary student is incapable of learning and passing science subjects. The method and processes of learning have combined to create loathing. So the students rather feel comfortable in the liberal arts where real world feel methods are employed.

Nwanekezi A.U. et ... al (2014) experimentation on student's misconception on heat and temperature concepts in physics still fell short of the theatre practice model. They explained that:

The control groups were taught using the traditional (talk-chalk) method with illustration on various topics on heat and temperature concepts such as: heat as a form of energy, heat measurement, heat conductivity and transfer... while the experimental groups were taught same concepts accompanied with experimentation after teachers demonstration.

There is the need to break rigid boundaries of teaching and learning. The role play method was not employed with this controlled and experimental groups. May be the teachers are not aware that role play can be used to further expand the learning capacity of the students.

The teachers need to be trained on the model to test its veracity. The mindset of the teachers is already made up on the students and so both are victims of circumstances. The teachers go through stress to impart the knowledge of science to students who see science subjects as better pills to swallow.

Ugal G.A. (2002:106) supports this as he puts it that:

Attention is immediate, when its object is interesting in itself. An attention to music is immediate because it is interesting in itself. When you attend to a lecture in mathematics without feeling any interest but only the purpose of passing an examination, your attention is derived or apperceptive.

The interest of the students are not sustained in the teaching of science subjects. The students do not have enough interest and attention in the learning process. Because of the model of teaching the students have already generated a dislike for the science subjects and the model of teaching the subjects compound the problem for the students. As already noted the veracity of the theatre practice model can be tested through experimentation.

The various steps in mathematics calculations can be taught using music, rhymes and dance. In the primary stage of calculations rhymes are used as "five green bottles standing on the walls and one green bottle falls, four green bottles will be standing on the wall". As simple as this song appears, it as a demonstration of numbers and subtraction in simple arithmetic. Same thing simple biology is studied when the human parts or parts of the body are used in singing and dancing, "my head, shoulder, my knees, my toes, they all belong to Jesus. Even days of work or months of the year are used in rhymes and are made graphic on the child's memory. The effect of this method is such that the rhyme or the song provides a conditional response to the memory of the child. No effort should be spared in creating the desired effect for sustaining the learning of science subjects. The problem has assumed enough concern for students, teachers, parents and government. The controlled groups and experimental groups should be furthered enhanced with robust theatrical activities to spur interest and developed the right attitude. The learning of chemistry can benefit from the same method shift to enhance a generation of science motivated students.

\section{CONCLUSION}

The use of theatre practice as a model of learning in secondary schools, has been the pursuit of this paper. The traditional methods of teaching have created alienating processes particularly in the teaching and learning of science subjects. The presentation of this model is not that the model is mutually exclusively perfect but as an additional model. The model is advocated due to the gaps created by the traditional methods. The talkchalk, the experiment and the theatre practice models can complement each in enhancing as well as developing the right attitude by students to the learning of science subjects. The Nigerian science student goes through poor curriculum, personnel and institutional framework. It is by sheerluck and determination that the few pass their science subjects. Therefore, this paper is a wake up call for the over haul of the system that has hindered the effective learning of science subjects at the secondary school level. The majority of the students that dread science subjects do this, not because the subject are difficult but due to the impression the method of learning has created. 


\section{REFERENCES}

[1]. Chioma O.C.C. and Umera-Okeke P. (2013) Effective Strategies for Activating Students Background Knowledge in Comprehensive. In the Crab Journal, Port Harcourt: University of Port Harcourt Press.

[2]. Chukwueggu C.O. C. (2012) The Use of Drama and Dramatic Activities in English Language. In the Crab Journal, Port Harcourt, University of Port Harcourt Press.

[3]. Igwe L.E.B. et al (2014) The Rationality of Planning and Implementing Vocational and Technical Education for Technological Development in Nigeria. In Trends in Educational Studies Journal. Port Harcourt: SABCOS Publishers.

[4]. Ken-Aminikpo F.I. (2014) Motivational Strategies for Developing Theatre Performance Skills of Children. In Trends in Educational Journal Port Harcourt: SABCOS Publishers.

[5]. Nwanekezi A.U. et al (2014) Teaching Strategies to remedy Secondary School Students Misconception on Heat and Temperature Concept in Physics. In Trends in Educational Studies Journal, Port Harcourt: SABCOS Publishers.

[6]. Ugal, G.A. (2002) Introduction to Psychology, Calabar: Clearliness Publishers. 